\title{
Unmanned Transportation Applications at First Level Air Infrastructure (FLAI)
}

\author{
Veikko Tapio KAURILA ${ }^{1}$ \\ ${ }^{a}$ Science and Engineering, University of Derby, Markeaton Street DE22 3AW, UK
}

\begin{abstract}
Increasing complexity of infrastructure has growing need for maintenance that is accumulating cost in the long run. This report compares the simulation of traditional transportation to an aviation alternative. The focus is on the cost effectiveness and power efficiency of Vertical/Short Take-Off and Landing (V/STOL) vehicles. Author's motivation in this topic is from the project of designing a VTOL vehicle for multimodal transportation. The simulation of 100.000 people demonstrates efficiency of aviation infrastructure. Counting 11 billion for traditional infrastructure and 4 billion for equivalent VTOL vehicle carrying capacity. Affecting factors are energy, transportation modes, infrastructure and operation average the results. The simulation is simplistic model of infrastructure with normally distributed traffic, neglecting the effect of transition between vehicles, and the effect of wind magnitude and direction. The aviation method reduced distance up to $82 \%$ made travel time $92 \%$, consumed $88 \%$ of the energy, when emissions show relatively equivalent quantity on both applications. The results of FLAI imply economic advantages over traditional infrastructure and suggest further research into the safe adoption of aviation infrastructure.
\end{abstract}

Keywords. Traffic congestion, Infrastructure, Mobility, Aeronautical engineering

\section{Introduction}

Road infrastructure and its maintenance devoted resources increase exponentially, unless traffic can be redirected to other transportation modes. V/STOL vehicle design has the effect of helicopter and efficiency of an airplane. Whilst not readily available in physical infrastructure due to heavy regulation and maintenance, this report compares their integration on the existing infrastructure by the efficiency of energy, mode, infrastructure, and operation. It is expected that ethereal path is faster but consumes more energy.

Table 1. Objects for the simulation

\begin{tabular}{rrrr}
\hline \multicolumn{1}{c}{ Energy } & Mode & Infrastructure & Operations \\
\hline Fossil Fuels & Car/ Taxi/Bus & Road/Rail/Ether & Population \\
Nuclear Fission & Train/Metro & Prevailing wind & Passengers \\
Hydroelectric & Airplane & Transport hubs & Conveniency \\
Wind & Helicopter & Fuel stations & Idle operation \\
Photovoltaics & Ferry & & \\
Biomass & Pedestrians & & \\
Hydrogen & VTOL & & \\
\hline
\end{tabular}

\footnotetext{
${ }^{1}$ Corresponding Author. veikko.kaurila@ietvolunteer.org
} 


\section{Methods}

Figure 1. A and B models illustrate traditional and V/STOL hierarchies and datapoints. The nodes A to $\mathrm{N}$ represent all terminals that an individual can stop by. Different arrow colors represent different transportation modes and the colored shapes dominating areas.

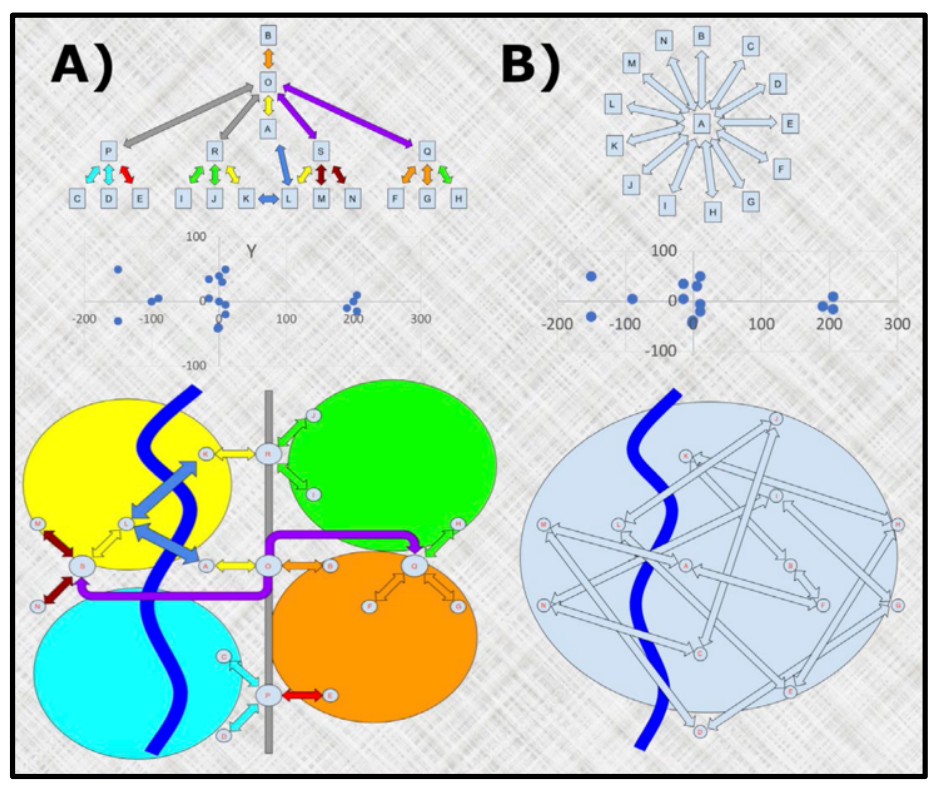

Figure 1. Data points for A) traditional infrastructure, B) VTOL infrastructure.

Table 2. show the different transportation modes and underlying investments. For comparison, the simulation A. has $63 \mathrm{~km}$ of road that cost $16 \mathrm{mf}$, there are 24 thousand people using cars that cost $176 \mathrm{~m} £$, and construction for urban parking has cost $20 \mathrm{~m} £$; same comparison to rail, bus, metro, sea, aviation, and pedestrian. Whereas simulation B. has $1273 \mathrm{~km}$ of ether that cost nothing, there are 100 thousand people using vehicles that cost $3.75 \mathrm{M} £$ and landing areas that cost $50 \mathrm{~m} £$. The model A. consider travelers who need more than one mode to reach destination, such as taking a taxi from the airport.

Table 2. Object parameters

\begin{tabular}{rrrrrrrr}
\hline Mode & $\begin{array}{r}\text { Distance } \\
(\mathbf{k m})\end{array}$ & Users & $\begin{array}{r}\text { Density } \\
(\mathbf{p p l} / \mathbf{k m})\end{array}$ & $\begin{array}{r}\text { Vehicle } \\
(\mathbf{t} \mathbf{f})\end{array}$ & $\begin{array}{r}\text { Infrastr. } \\
(\mathbf{t} \mathbf{)})\end{array}$ & $\begin{array}{r}\text { Terminal } \\
(\mathbf{t} \mathbf{)})\end{array}$ & $\begin{array}{r}\text { Budget } \\
(\mathbf{t} \mathbf{)})\end{array}$ \\
\hline Road & 63 & 23529 & 371 & 176471 & 16509 & 19608 \\
Rail & 240 & 35294 & 147 & 132353 & 224000 & 7647 \\
Bus & 37 & 17647 & 483 & 66176 & 9491 & 7500 \\
Metro & 206 & 88235 & 429 & 330882 & 1284093 & 7868 \\
Marine & 75 & 11765 & 157 & 35651 & & 10000 \\
Airspace & 800 & 29412 & 37 & 7352941 & & 1524510 \\
Helicopter & 129 & 235 & 2 & 29412 & & 441 \\
Pedestrian & 4 & 11765 & 236 & & & & \\
& & & & & & & \\
Total & 1555 & 217882 & 141 & 8123886 & 1534093 & 1577573 & 11235552 \\
V/STOL & 1273 & 100000 & 79 & 3750000 & 0 & 50000 & 3800000 \\
\hline
\end{tabular}


Figure 2. A-E show variables affecting energy, application, infrastructure, and operation.

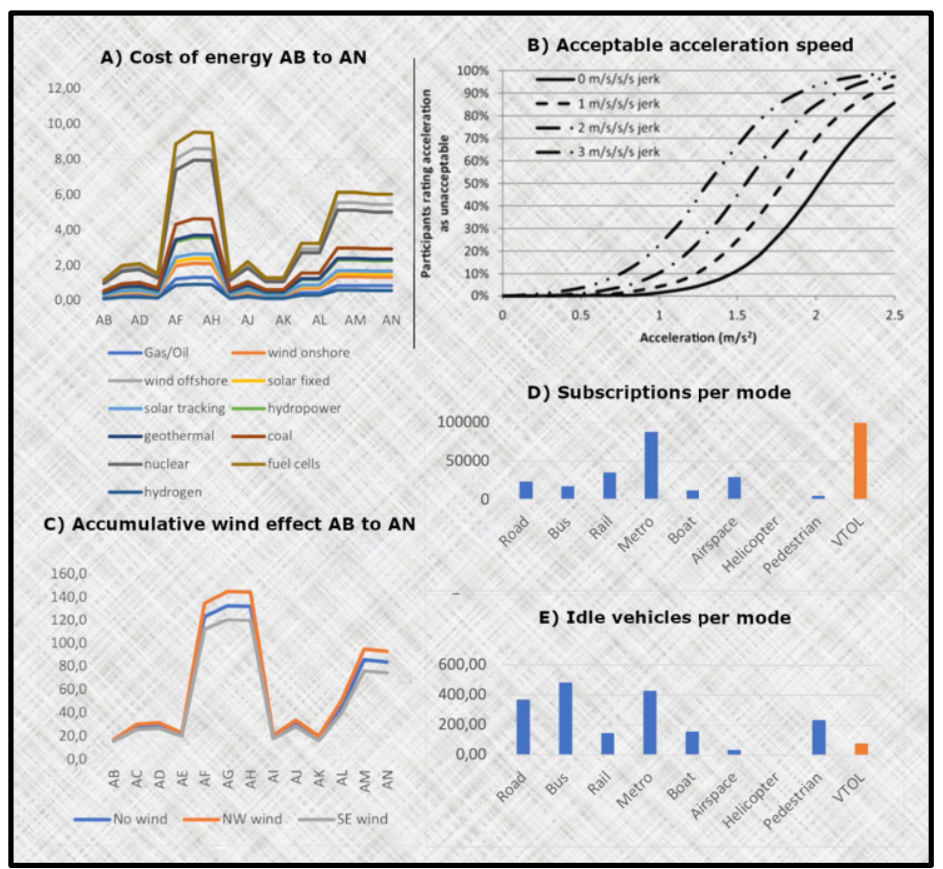

Figure 2. Critical analysis of a) energy, b) applications, c) infrastructure, and d and e) operations

Table 3. is the list of parameters used to simulate models A and B. The objects have no transition time and travel the entire path at full speed. The range limit the continuous travel by decelerating to zero velocity and accelerating again to full speed. The fuel type is affecting the emission and power consumed per kilometer.

Table 3. Simulation parameters

\begin{tabular}{rrrrrrr}
\hline Object & $\begin{array}{c}\text { Range } \\
(\mathbf{k m})\end{array}$ & $\begin{array}{c}\text { Acceleration } \\
(\mathbf{m} / \mathbf{s} \mathbf{2})\end{array}$ & $\begin{array}{c}\text { Velocity } \\
(\mathbf{k m} / \mathbf{h})\end{array}$ & Fuel & $\begin{array}{c}\text { CO2 } \\
(\mathbf{g} / \mathbf{k m})\end{array}$ & $\begin{array}{c}\text { Power } \\
(\mathbf{W} / \mathbf{k m})\end{array}$ \\
\hline Car & 100 & 2 & 100 & Fossil & 100 & 400 \\
Bus & 20 & 2 & 80 & Fossil & 90 & 300 \\
Metro & 40 & 2 & 100 & Fossil & 0 & 200 \\
Train & 100 & 2 & 100 & Fossil & 40 & 200 \\
Airplane & 1000 & 2 & 800 & Fossil & 100 & 300 \\
Ferry & 100 & 2 & 80 & Fossil & 120 & 60 \\
Helicopter & 100 & 10 & 200 & Fossil & 50 & 2600 \\
Pedestrian & 1 & 0.1 & 10 & Biomass & 0 & 0 \\
VTOL & 100 & 10 & 100 & Renewable & 150 & 600 \\
\hline
\end{tabular}




\section{Measurements}

Figure 3. A. show increase in energy consumption over long distances ( $\mathrm{AF}-\mathrm{AH})$ and equivalent on short distances, B. show reduction on each path (AB to $A N$ ), C. show reduction in overall duration, but technically not competitive with plane or helicopter.

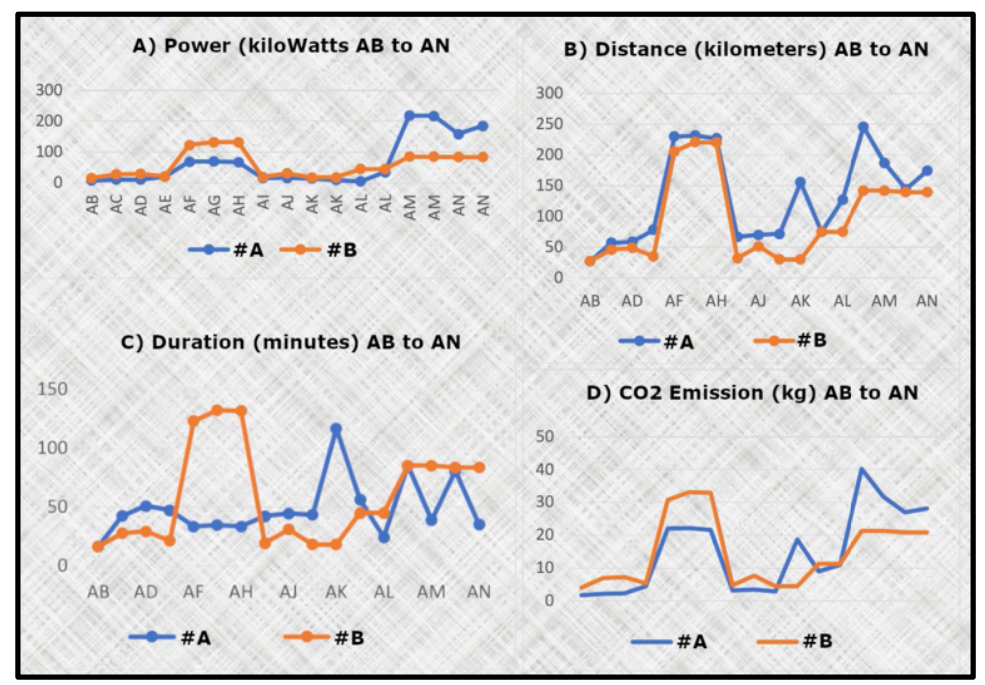

Figure 3. Simulation of the parameters a) power, b) distance, c) duration, d) $\mathrm{CO} 2$ emissions

\section{Results}

The average of each simulation in Figure 3. are shown in Figure 4., demonstrating that generally VTOL produces as much emission to traditional infrastructure, but has much less distance to travel, spends less time, and consumes less power respective to the graph.

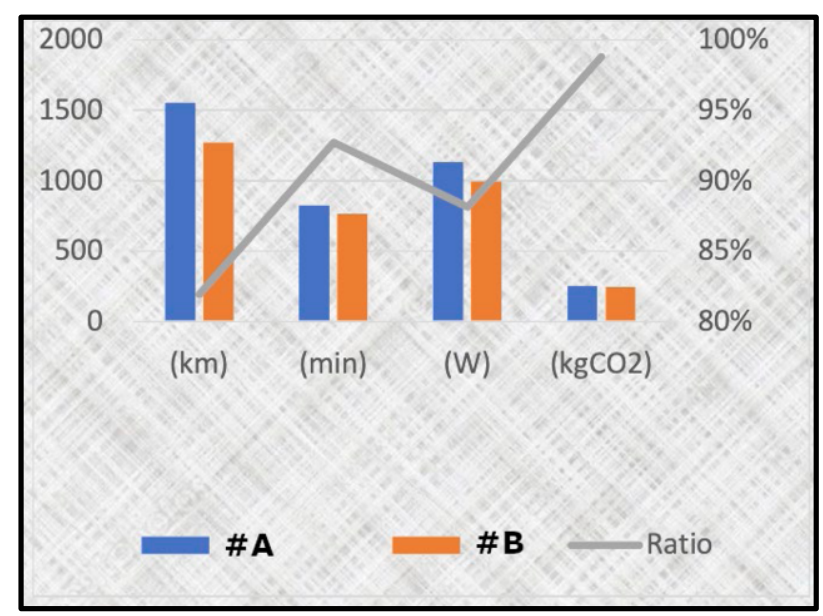

Figure 4. Results of the simulation 


\section{Discussion}

Technical decisions on both models, A and B, were based on the current infrastructure. Model A cannot fully demonstrate the effect of transitioning from one mode to another or traffic jams. Model B assumes the amount of traffic remain the same. To include the model A transition requires stochastic analysis of traffic patterns, which can be used to create abstract simulation for model B traffic. However, the effect is negligible within the scope of this report. Major findings were the reduction in distance and integration cost. Power, emission, mobility and duration are subject to closer analysis of the traffic.

This implies the feasibility of V/STOL vehicle commercialization, which is already agenda for many carmakers ${ }^{[3]}$ and regional development. ${ }^{[2]}$ Due uncertainties the adaptation could be most effective when the vehicles adopt pay-as-you-go services. ${ }^{[4]}$ While consuming more power, research has shown good results in utilizing solar energy during a flight. ${ }^{[5]}$ Delivery on demand at specific location is showing general interest in logistics ${ }^{[6]}$ and transportation. ${ }^{[7]}$ Automation of these vehicles may be essential due the amount of training required on manually operated vehicles. Digitally driven trajectory would be able to avoid areas sensitive to noise, which would equal to car generated tire noise. And integrate technology to avoid collusion with other vehicles in the air. ${ }^{[1]}$ The application requires more resiliency from manmade hazards than land vehicles due the adverse effects of falling vehicles. The adaptation will make new jobs and make others obsolete, which imply the need for new skills. This intelligent control come with serious cyber threat that have potentially more adverse effect than land vehicles. Security is developing and possible cyberattacks might be avoided with right technologies. ${ }^{[8]}$

\section{Conclusion}

The comparison of traditional infrastructure to flying cars within 100,000 user economy presented feasible result for the integration of V/STOL vehicles. Comparing the effects of energy, mode, infrastructure and operations, the results indicate better performance at short distances, worse or equivalent in longer distance when the factors are averaged.

Average savings in implementation reduced from 11 billion to 4 billion pounds, shorter routes by $18 \%$, faster journeys by $7 \%$, more energy efficient paths by $12 \%$ and emissions about the same. The simulation is crowded, and the natural traffic patterns are mitigated. The transition time between traditional model can cause more difference in the duration and power consumption. Realistic traffic patterns might increase the benefit of using V/STOL vehicles. Technical and political challenges exist in the integration of the vehicle. Security technology and capital allocation are open for further research.

The physical infrastructure of V/STOL vehicles emerge data driven control and development of new skills. While enabling efficient transportation alternative, the mode is adaptable to different environments, allowing habitation of environments otherwise out of reach, and deployment of architecture to achieve most functional infrastructure. Further research is made on: Safe adoption of emerging technologies: review of the skills needed and readiness of the engineering sector; Safety of digital and data driven systems: capability mapping; And Safety of physical infrastructure. 


\section{Acknowledgements}

This report was conducted and constructed on individual basis during organized lectures and supplemented by independent research. Module tutor: Dr. Mahmoud Shafik.

\section{Declaration of Conflicting Interests}

The author(s) declared no potential conflict of interest with respect to the research, authorship, and/or publication of this article.

\section{Funding}

The author(s) received no financial support for the research, authorship and/or publication of this article.

\section{References}

[1] Collusion-Avoidance solution (2019). Iris Automation Drone collision-avoidance solution. [online]. (Last updated 29 April 2019). Available at: https:/www.wearefinn.com/topics/posts/iris-automationlaunches-supercomputer-drone-collision-avoidance-solution [Accessed 1 March 2020].

[2] White House priorities eVTOL for 2021 (2019) R\&D that enables eVTOL among other applications [online]. (Last updated 18 September 2019) Available at: https://evtol.com/news/white-houseprioritizes-evtol-2021/ [Accessed 1 March 2020].

[3] Flying car within 10-years (2019) Netherlands Aerospace centre Memorandum of Understanding to develop an autonomous eVTOL flying car within ten years. [online]. (Last updated 26 April 2019). Available at: https://www.wearefinn.com/topics/posts/pal-v-and- nlr-to-develop-autonomous-evtolflying-car- expect-to-launch-within-10-years [Accessed 1 March 2020].

[4] Pay as you go public transport (2018) Combine all different transport modes as monthly packages [online]. (Last updated 10 May 2018). Available at: https://www.wearefinn.com/topics/posts/the- spotify-oftransportation-and-getting-aviation-on- the-playlist [Accessed 1 March 2020].

[5] Solar electric powered unmanned aircraft (2020) Plug the air gap between aircraft and satellite. [online]. (Last updated 17 February 2020). Available at: https://www.wearefinn.com/topics/posts/solar- poweredunmanned-aircraft-makes-first-flight [Accessed 1 March 2020].

[6] Small packages delivery (2019) on demand to specific destinations in only few minutes [online]. (Last updated 26 April 2019). Available at: https://www.wearefinn.com/topics/posts/alphabet- s-wingaviation-first-to-receive-faa-approval-for- drone-delivery [Accessed 1 March 2020].

[7] Role of flying car in sustainable economy (2019) VTOLs offer fast, predictable transportation and could have a niche role in sustainable mobility [online](last updated 9 April 2019) Available at: $h$ ttps://www.nature.com/articles/s41467-019-09426-0 [Accessed 1 March 2020].

[8] New security technology (2019) detects malicious cyberattacks on drones, cars, and robots [online]. (Last updated 26 February 2019). Available at: https://spectrum.ieee.org/tech- talk/computing/embeddedsystems/new-security- technology-detects-attacks-on-sensors-controlling- numerous-applicationsincluding-drones-cars-and-robots?utm campaign=Partner+Piece\&utm conten $\mathrm{t}=\mathrm{https}: \% 2 \mathrm{~F} \% 2 \mathrm{Fspectrum}$. ieee.org\&utm_medium $=$ organic\&utm_source=linkedin [Accessed $1 \mathrm{March}$ 2020]. 